\title{
Viscosity, Relaxation and Stability of Natural Rubber
}

\author{
Jiří Maláč*
}

Department of Polymer Engineering, Faculty of Technology, Tomas Bata University in Zlín, CZ-762 72 Zlín, Czech Republic

\begin{abstract}
Mooney viscosity and Mooney relaxation of unaged and oven aged SMR L natural rubber samples were studied. The viscosity was characterized by $\mathrm{ML}(1+4) 100^{\circ} \mathrm{C}$ and the rate of stress relaxation by the exponent $a$ in a power law $M=k(t)^{a}$. With the increasing time of oven aging at $140^{\circ} \mathrm{C}$ the decrease of both viscosity and stress relaxation rate exponent were observed. Aging of raw natural rubber can therefore be studied by Mooney viscosity and Mooney relaxation tests and obtained results are sensitive enough to be used for characterization of raw natural rubber stability.
\end{abstract}

Keywords: Viscosity, relaxation, stability, natural rubber.

\section{INTRODUCTION}

Natural rubber (NR) is the only non-synthetic elastomer in wide use. Derived from the milk-like liquid of the Hevea tree, natural rubber latex contains many organic and inorganic impurities. Natural rubber and synthetic polyisoprene share the same monomer chemistry (isoprene is the building block of these polymers). Synthetic polyisoprene consists of up to $99 \%$ rubber hydrocarbon, while natural rubber is usually around 93\% rubber hydrocarbon and molecular weight distribution of natural rubber is widely variable [1].

Some of the non-rubber substances such as lipids, carotenoid pigments, sterols, triglycerides, glycolipids and phospholipids can influence the final properties of rubber, such as compounded vulcanization characteristics and classical mechanical properties [2]. Molecular weight distribution influences viscosity and elasticity of raw natural rubber and different impurities in raw NR influence the rubber hydrocarbon stability in processing and applications.

Mooney viscosity test is one of the most common procedures performed in the rubber industry today. It is commonly used to measure the viscosity of raw rubbers and to characterize the quality of both natural and synthetic rubber. The Mooney viscometer consists of rotating a serrated rotor imbedded in a rubber specimen, contained within a sealed, pressurized cavity. From its constant speed, the rotor experiences a given resistance to rotation that is recorded as torque in N-m. ASTM D 1646 describes the algorithm used to convert this torque into Mooney Units (MU). The actual Mooney viscosity to be reported is the value preceding the specified time of reading. This has to be defined because of the thixotropic nature of rubber (where the measured viscosity changes with time) [3].

However, it is common to find two polymers with the same complex viscosity, but with very different elastic and viscous components. A clearer distinction in such cases

*Address correspondence to this author at the Department of Polymer Engineering, Faculty of Technology, Tomas Bata University in Zlín, CZ-762 72 Zlín, Czech Republic; Tel: +420 576031 330; E-mail: jmalac@ft.utb.cz would thus mean separating the complex response into its constituent parts and studying each of them [4].

At Mooney stress relaxation test the Mooney viscometer stops the rotation of its rotor very quickly after completion of the viscosity test. After stopping of rotor the torque values are recorded. The stress relaxation of rubber can usually be described through power law model

$\mathrm{M}=\mathrm{k}(\mathrm{t})^{\mathrm{a}}$

where:

$M=$ torque units from the Mooney stress relaxation test,

$k=$ a constant equal to torque $1 s$ after the rotor has stopped, and

$a=$ an exponent that measures the rate of stress relaxation.

The Eq. (1) we can convert into a log-log expression and get

$\log \mathrm{M}=a(\log t)+\log k$

If we place relaxation data in a log-log plot, and if the rubber is complying with the power law model in Eq. (1) and Eq. (2), the stress relaxation becomes a straight line.

The slope $a$ is then one method of quantifying uncured rubber elasticity. A steep slope indicates less uncured elasticity and less elasticity can mean better processing. Mooney stress relaxation can therefore provide additional quality information which Mooney viscosity test cannot provide [3].

Recent results for natural rubber showed that a triexponential generalized Maxwell model in many cases allowed better description of relaxation curve for the samples studied than the traditionally used power law [4]. The rate of stress relaxation can be determined also for example by measuring the time for a $95 \%$ (T-95) decay of the torque at the conclusion of the viscosity test [5]. These possibilities can be used when the relaxation data in a log-log plot are not a straight line.

Since natural rubber is an unsaturated elastomer, it is readily susceptible to oxidation. This can affect both the processing qualities of the rubber and also the final com- 
pounded rubber mechanical properties [5]. For raw rubber stability testing various accelerated procedures using ovens or infrared lamps have been used with visual assessment of deterioration. A more satisfactory procedure based on the measurement of raw rubber plasticity after oven aging at $140^{\circ} \mathrm{C}$ for $30 \mathrm{~min}$ is known as the plasticity retention index (PRI) and is calculated from:

$\mathrm{PRI}=\frac{P_{a}}{P_{u a}} \times 100$

where: $P_{a}=$ aged plasticity and $P_{u a}=$ unaged plasticity [6].

The principle of plastimeter procedures is basically to measure the deformation of a cylindrically cut, uncured rubber specimen after it has been subjected to a constant compressive force between two parallel plates for a specified time period at a specified test temperature. In a way "plasticity" and "viscosity" define the same property, but have the opposite meaning. While viscosity is defined as the resistance to plastic deformation, the term plasticity refers to the "ease of deformation" for an uncured rubber specimen. Indeed, plastimeters are very simple, crude methods for measuring the flow of a rubber sample [1]. In this work, we studied oven aging of raw natural rubber by Mooney viscosity and Mooney relaxation tests.

\section{EXPERIMENTAL}

The unmassed (i.e. not milled) raw natural rubber type SMR L was used. The samples of SMR L rubber were tested either unaged or oven aged at $140^{\circ} \mathrm{C}$ for $0.5,1$ or 2 hours (as strips with thickness of about $1 \mathrm{~cm}$ ).

\section{RESULTS}

As an example, in Fig. (1) the Mooney viscosity and Mooney relaxation of unaged SMR L sample were measured at $100^{\circ} \mathrm{C}$ and torque in Mooney Units (MU) was recorded. After preheat time $1 \mathrm{~min}$ and test running time $4 \mathrm{~min}$ the Mooney viscosity $M L(1+4) 100^{\circ} \mathrm{C}$ was obtained. The Mooney viscosity is therefore value of torque (in MU) $5 \mathrm{~min}$ from the test beginning. After stopping of rotor (at this $5 \mathrm{~min}$ time) the stress relaxation of rubber sample (i.e. decrease of torque values in MU) was measured for next $3 \mathrm{~min}$.

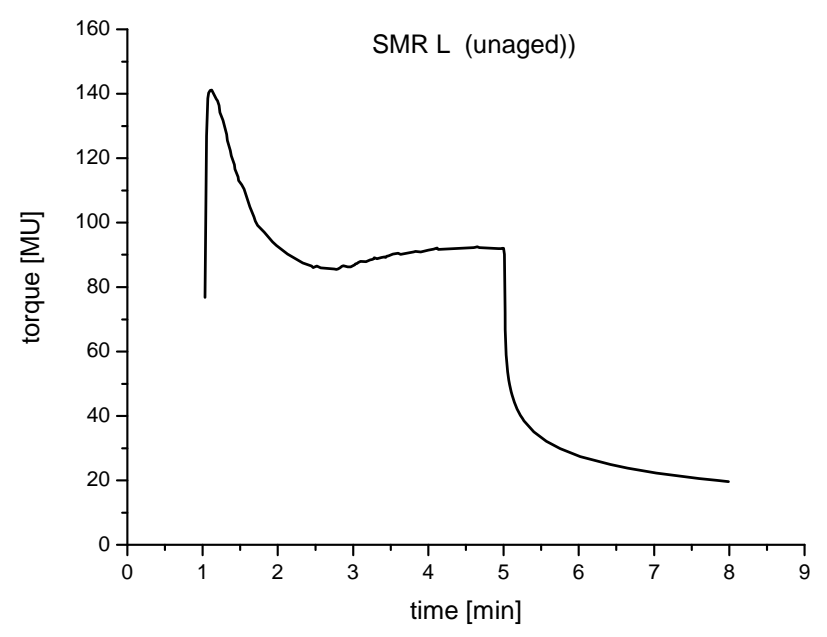

Fig. (1). Mooney viscosity and Mooney relaxation for unaged SMR $\mathrm{L}$ raw natural rubber.
In this work we tested also the oven aged SMR L raw natural rubber. For this purpose the samples of SMR L were aged in oven at $140^{\circ} \mathrm{C}$ for $0.5,1$ or 2 hours. Data obtained for our unaged and oven aged samples by used Mooney viscometer and evaluated by its software are presented in Table $\mathbf{1}$ and in Figs. (2, 3 and 4).

Table 1. Mooney Viscosity and Relaxation Values

\begin{tabular}{|c|c|c|c|}
\hline $\begin{array}{c}\text { Value Aging } \\
{[\mathbf{h}]}\end{array}$ & $\begin{array}{c}\text { ML(1+4) } \\
{[\mathbf{M U}]}\end{array}$ & $\begin{array}{c}\text { Const. } \boldsymbol{k} \\
{[\mathbf{M U}]}\end{array}$ & $\begin{array}{c}\text { Exponent } \boldsymbol{a} \\
{[\log (\mathbf{M U}) / \log (\mathbf{s})]}\end{array}$ \\
\hline \hline $\mathbf{0}$ & 92.0 & 69.6 & -0.221 \\
\hline $\mathbf{0 . 5}$ & 90.7 & 69.3 & -0.252 \\
\hline $\mathbf{1}$ & 61.9 & 41.5 & -0.401 \\
\hline $\mathbf{2}$ & 33.7 & 18.5 & -0.508 \\
\hline
\end{tabular}

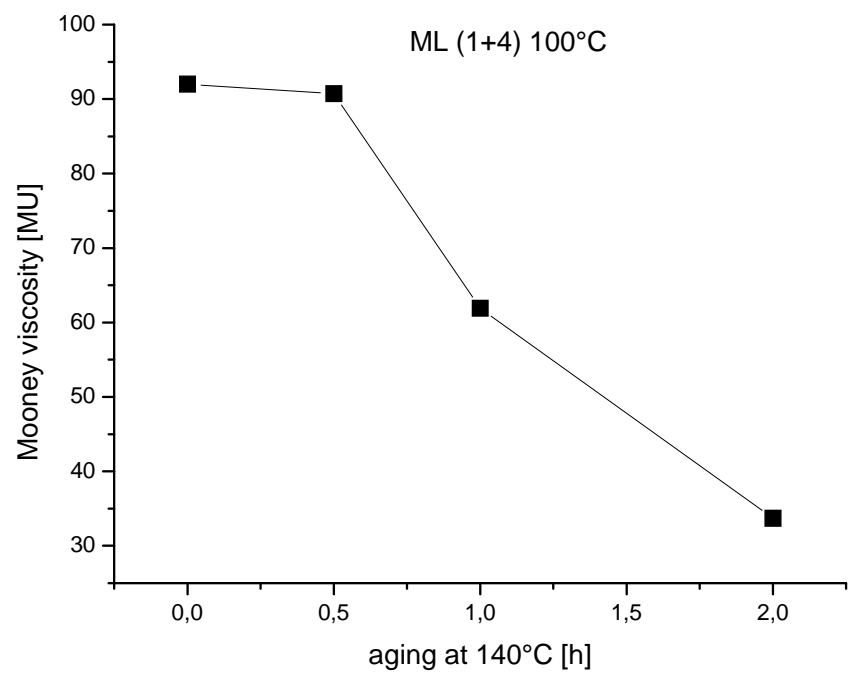

Fig. (2). Dependence of Mooney viscosity of SMR L samples on time of aging.

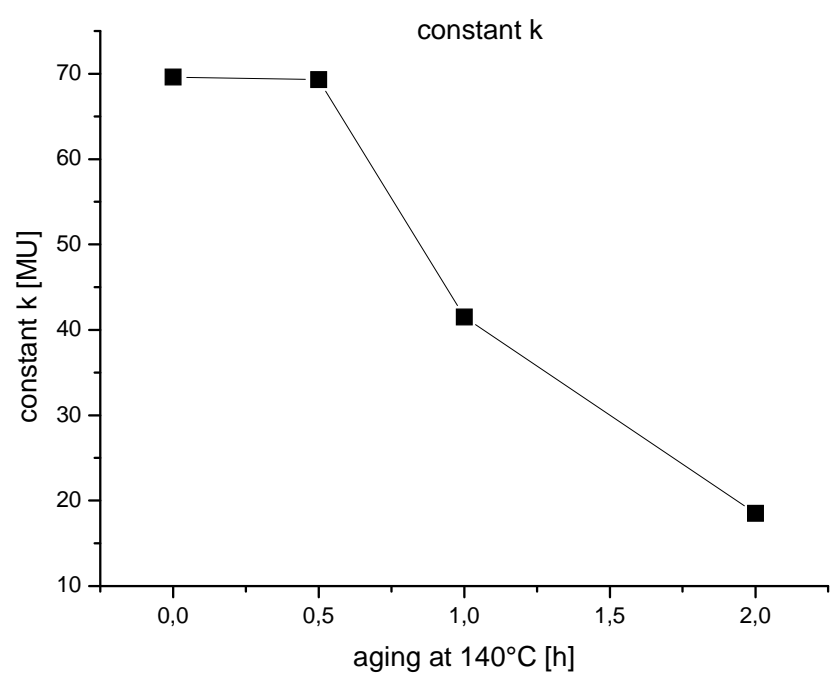

Fig. (3). Dependence of constant $k$ in Eq. (2) on time of aging. 


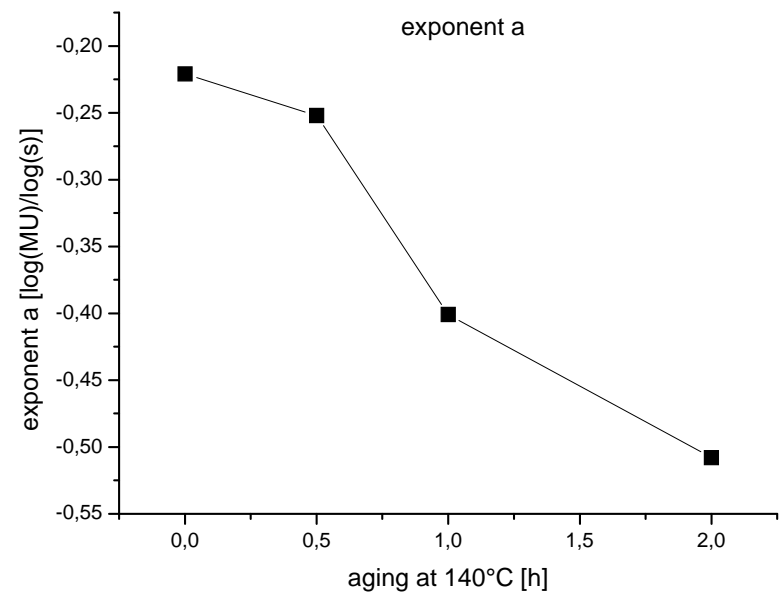

Fig. (4). Dependence of exponent $a$ in Eq. (2) on time of aging.

\section{DISCUSSION}

Values of Mooney viscosity, constant $k$ and exponent $a$ in Table 1 all decrease with increasing time of oven aging at $140^{\circ} \mathrm{C}$, but differences between values of unaged and $30 \mathrm{~min}$ aged SMR L sample are evidently too small to be suitable for evaluation of stability of this natural rubber. Values after $1 \mathrm{~h}$ of aging are significantly lower than these for unaged SMR L and seem to be sensitive enough for characterization of the SMR L stability.

Although not linear, there is an empirical relationship between Mooney viscosity and weight average molecular weight $M_{w}$ [5]. The decreasing values of Mooney viscosity of SMR L samples with time of oven aging at $140^{\circ} \mathrm{C}$ in Fig. (2) could therefore indicate decreasing weight average molecular weight of SMR L natural rubber with time of oven aging at given conditions.

Raw polymers and rubber compounds have been shown to follow the "Power Law" during Mooney stress relaxation. Most of the tested polymers so give a strait regression line on a log-log scale but some a curved regression line [7, 8]. Thus how good describe the constant $k$ and exponent $a$ in

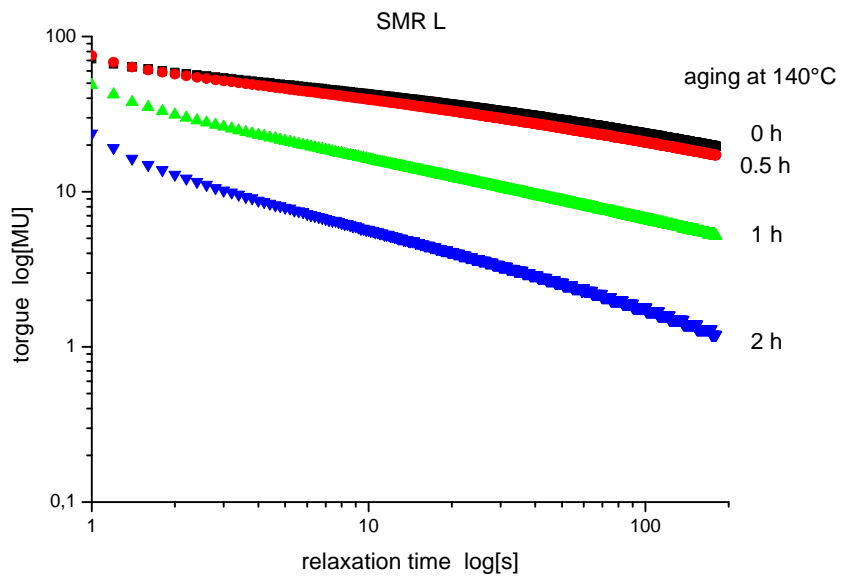

Fig. (5). Torque values vs. relaxation time in $\log -\log$ plot and time of oven aging at $140^{\circ} \mathrm{C}$.
Table 1 the relaxation behaviour of our unaged and oven aged SMR L rubber samples? In Fig. (5) we placed relaxation data of our samples in a log-log plot. In all cases we obtained nearly straight line, which means that the Mooney stress relaxation of our unaged and aged SMR L rubber is complying with the power law model in Eq. (1) and Eq. (2).

The decrease of constant $k$ in Eq. (2) with time of oven aging at $140^{\circ} \mathrm{C}$ in Fig. (3) seems to be similar to the decrease of Mooney viscosity with time of oven aging in Fig. (2). As we can see in Fig. (6), the dependence of constant $k$ on Mooney viscosity is in fact linear $(r=0.99916)$. The constant $k$ therefore cannot provide additional information about oven aging of SMR L rubber to that of Mooney viscosity.

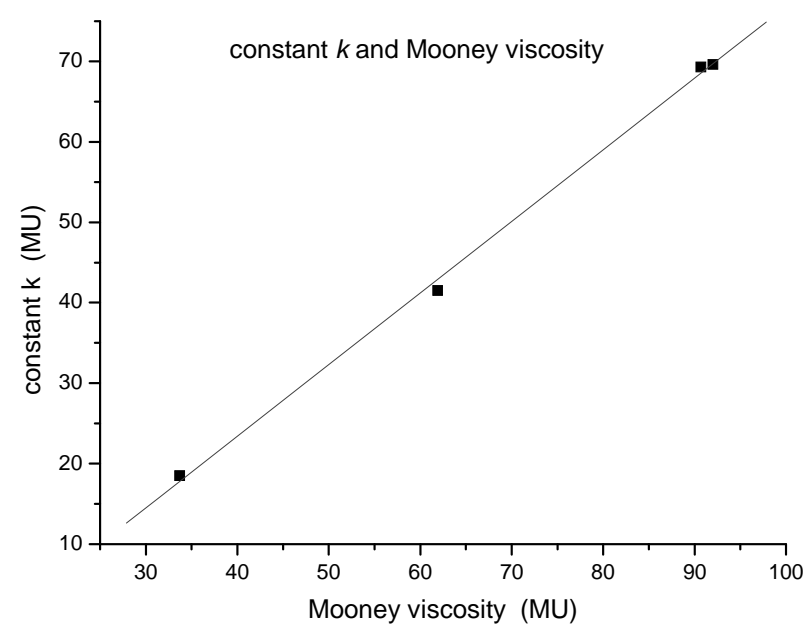

Fig. (6). Obtained dependence of constant $k$ on Mooney viscosity.

The rate of Mooney stress relaxation can correlate with molecular structure characteristics such as molecular weight distribution, chain branching and gel content. It can also be used to give an indication of polydispersity [5]. The decreasing values of exponent $a$ with time of oven aging in Fig. (4) are so probably indicative of narrowing molecular weight distribution of SMR L with time of oven aging. Both the decrease of Mooney viscosity and the decrease of exponent $a$ of SMR L samples could probably be explained by the main chain scission of natural rubber molecules at oven aging.

\section{CONCLUSIONS}

Mooney viscosity and Mooney stress relaxation of raw natural rubber SMR L samples depend on time of oven aging at $140^{\circ} \mathrm{C}$.

Mooney stress relaxation of unaged and oven aged SMR $\mathrm{L}$ rubber is complying with the power law model (relaxation data of samples in a log-log plot give nearly straight line).

The values of Mooney viscosity and values of constant $k$ and exponent $a$ (characterizing Mooney relaxation) of raw natural rubber SMR L samples decrease with increasing time of oven aging at $140^{\circ} \mathrm{C}$.

The dependence of constant $k$ on Mooney viscosity is linear and constant $k$ therefore cannot provide additional 
information about oven aging of SMR L rubber to that of Mooney viscosity.

Aging of raw natural rubber can therefore be studied by Mooney viscosity and Mooney relaxation tests and obtained results are sensitive enough to be used for characterization of raw natural rubber stability.

\section{ACKNOWLEDGEMENT}

The author thanks the Ministry of Education, Youth and Sports of the Czech Republic (MSM-7088352101) for financial support.

\section{REFERENCES}

[1] Dick, J.S. Ed. Rubber Technology: Compounding and Testing for Performance. Carl Hanser Verlag: Munich, 2001.

[2] Rogers, M.B.; Tracey, D.S.; Waddell, W.H. Production, Classification and Properties of NR. Rubber World, 2005, 232(5), 32.
[3] Dick, J.S., Ed. Basic Rubber Testing: Selecting Methods for a Rubber Test Program. ASTM Stock Number: MNL39, 2003.

[4] Ehabe, E.; Bonfils, F.; Aymard, C.; Akinlabi, A.K.; Beuve, J.S.; Modelling of Mooney Viscosity Relaxation in Natural Rubber. Polym. Test., 2005, 24, 620 .

[5] Rogers, M.B.; Tracey, D.S.; Waddell, W.H. Production, Classification and Properties of NR - Part 2." Rubber World, 2005, 232(6), 41.

[6] Brown, R. Physical Testing of Rubber, $4^{\text {th }}$ ed., Springer Science+Business Media, USA, 2006

[7] Burhin, H.G.; Thompson, M.; Spreutels W. MV2000 Mooney Viscometer: Mooney Relaxation Measurements on Raw Polymers and Compounded Rubber Stocks, Meeting of the Rubber Division, American Chemical Society, Detroit, Michigan, October 17-20, 1989.

[8] Burhin, H.G.; Spreutels W.; Sezna, J. MV2000 Mooney Viscometer: Mooney Relaxation Measurements on Raw Polymers and Compounded Rubber Stocks. Kaut. Gummi Kunststoffe, 1990, 43, 431.

(C) Jiř́ Maláč; Licensee Bentham Open.

This is an open access article licensed under the terms of the Creative Commons Attribution Non-Commercial License (http://creativecommons.org/licenses/by-nc/3.0/) which permits unrestricted, non-commercial use, distribution and reproduction in any medium, provided the work is properly cited. 